\title{
Características da carcaça de caprinos mestiços Anglo-Nubiano, Boer e sem padrão racial definido
}

\author{
Evaluation of carcass characteristics of crossbred Anglo-Nubian, Boer and \\ undefined breed goats
}

\section{Antônio Nunes de Oliveira' ${ }^{\mathrm{I}}$ Arturo Bernardo Selaive-Villarroel ${ }^{\mathrm{II}}$ Antônia Lucivânia Sousa Monte ${ }^{\mathrm{III}}$ Roberto Germano Costa ${ }^{\text {IV }}$ Ludmilla Beliche Alves Costa ${ }^{\text {II }}$}

\section{RESUMO}

O objetivo deste trabalho foi estudar as características da carcaça de cabritos de três grupos genéticos: $3 / 4$ Anglo Nubiana ( $n=21)$, 3/4 Boer $(n=22)$ e Sem Padrão Racial Definido $(n=21)$. Os animais foram abatidos em três diferentes pesos: 20, 25 e $30 \mathrm{~kg}$ de peso vivo. Avaliaram-se as características de rendimento e conformação da carcaça, bem como as perdas por resfriamento. Os resultados mostraram que não houve interação entre o genótipo e o peso de abate em todas as variáveis estudadas. $O$ genótipo teve efeito significativo $(P<0,05)$ no rendimento e na conformação da carcaça, com os menores valores observados nos caprinos SRD, não havendo diferenças significativas entre os caprinos mestiços de Anglo-Nubiano $e$ de Boer. O peso ao abate influenciou também significativamente $(P<0,05)$ no rendimento e conformação da carcaça, com os menores valores observados nos caprinos abatidos com $20 \mathrm{~kg}$ de peso vivo, não se observando diferenças entre os grupos abatidos com $25 e$ $30 \mathrm{~kg}$ de peso vivo. O rendimento e conformação da carcaça aumentaram à medida que aumentou o peso de abate dos animais até os $25 \mathrm{~kg}$ de peso vivo. As perdas por resfriamento da carcaça não apresentaram variação significativa $(P>0,05)$ entre os grupos genéticos e entre os diferentes pesos de abate. Em conclusão, cabritos mestiços 3/4 Boer e 3/4 Anglo Nubiano apresentaram características similares de rendimento $e$ conformação de carcaça, sendo ambos superiores aos SRD, $e$, portanto, mais indicados para produção de carne.

Palavras-chave: cabrito, conformação, cruzamento, grupo genético, rendimento.

\section{ABSTRACT}

The aim of this work was to study the carcass characteristics of three genetic groups: $3 / 4$ Anglo-Nubian $(n=21)$,

\begin{abstract}
$3 / 4$ Boer $(n=22)$ and undefined breed $(n=21)$. The animals were slaughtered at three different weights: 20,25 and $30 \mathrm{~kg}$ of live weight. It was evaluated the yield and the conformation carcass characteristics as well as the losses by cooling. The results showed no interaction genetic group and slaughter weight in all studied variables. The genotype had significant effect $(P<0.05)$ on the yield and conformation carcass, with lower values observed for SRD goats, but without significant difference between Anglo-Nubian and Boer crossbreed goats. The slaughter weight influenced $(P<0.05)$ on the yield and conformation carcass, with the lowest values observed in the goats slaughtered with $20 \mathrm{~kg}$ of live weight. No significant differences were observed between the groups slaughtered with 25 and $30 \mathrm{~kg}$ of live weight. The yield and conformation carcass increased to the measure that the slaughter weight from the goats up to $25 \mathrm{~kg}$ increased. The losses by cooling presented no significant variation $(P>0.05)$ between genetic groups and weight at slaughter. In conclusion, 3/4 Boer and 3/4 Anglo-Nubian crossbreed kids had presented similar characteristics of yield and conformation carcass, both superior to the SRD, being therefore more indicated for meat production.
\end{abstract}

Key words: kids, conformation, cross-breeding, genetic group, yield.

\section{INTRODUÇÃO}

Nos últimos anos, tem-se observado um maior interesse dos pecuaristas em melhorar a criação dos pequenos ruminantes em função do aumento da demanda de carne no mercado consumidor. Nesse sentido, a carne dos ovinos e caprinos vem sendo apontada como uma alternativa

\footnotetext{
IFaculdade de Veterinária, Universidade Estadual do Ceará (UECE). Av. Paranjana, 1700, Campus do Itaperi, 60740-000, Fortaleza, CE, Brasil. E-mail: anunes@uece.br. Autor para correspondência.

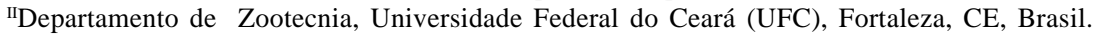

IIICentro de Ensino Tecnológico (CENTEC), Sobral, CE, Brasil.

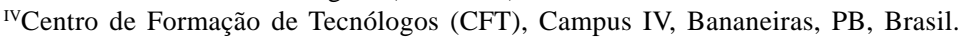


de fonte protéica economicamente viável para as condições do Nordeste.

Uma das alternativas capazes de melhorar a produção de carne caprina é o cruzamento das raças locais com raças exóticas especializadas para corte (CARDELINO, 1989), aliado a uma melhoria na alimentação dos animais através do uso de pastagens melhoradas e/ou cultivadas como suporte alimentar (ARAÚJO FILHO et al., 2002). Os cruzamentos são utilizados, entre outras razões, para se obter carcaça com melhor conformação e qualidade.

O peso da carcaça é um dos fatores que apresenta maior influência na valorização do animal, havendo, em alguns países, preferências acentuadas e preços diferenciados segundo o peso da carcaça. Esse peso varia com o tipo de animal (genótipo), o sexo e a velocidade de ganho de peso. Animais precoces, como, por exemplo, os da raça Boer, atingem o peso maduro em menos tempo que animais tardios, como, por exemplo, as raças nativas Moxotó, Canindé e Repartida, do Nordeste.

O conhecimento das características quantitativas da carcaça comercializada para a indústria por meio da determinação do rendimento, conformação e a composição tecidual, é de fundamental importância na busca da melhoria da qualidade potencial do produto final, ou seja, a carne.

O rendimento de carcaça é uma característica diretamente relacionada à produção e comercialização de carne (SAINZ, 1996), podendo variar em função de fatores intrínsecos ao próprio animal (genótipo, sexo, peso, idade) e/ou extrínsecos (alimentação, manejo, tipo de jejum) (SILVA SOBRINHO, 2001).

Tradicionalmente a avaliação da qualidade da carcaça é feita através da conformação, incluindo-se as características como tamanho e largura da carcaça e comprimento dos membros. A conformação está dada fundamentalmente pela base genética, sendo que as raças bem-conformadas, de clara aptidão para produção de carne, transmitem à sua descendência uma boa morfologia, enquanto as raças rústicas apresentam, em geral, carcaças estreitas (SAÑUDO \& SIERRA, 1996).

Na busca de animais com maior produção de carne, tem sido introduzidas na região Nordeste do Brasil, diversas raças exóticas, que têm gerado, através do uso de cruzamento, o aparecimento de novos tipos genéticos. Isso tem acontecido com as raças Anglo Nubiana e, atualmente, com a Boer em cruzamento com as raças e/ou tipos locais visando à obtenção de carcaças de qualidade superior.
O presente trabalho teve como objetivo avaliar as características da carcaça de cabritos oriundos do cruzamento de reprodutores sem padrão racial definido-SRD e das raças Anglo Nubiana e Boer com cabras sem padrão racial definido-SRD abatidos com diferentes pesos.

\section{MATERIAL E MÉTODOS}

Foi avaliado um total de 64 caprinos mestiços pertencentes a três grupos genéticos: $3 / 4 \mathrm{AN}$ $\mathrm{X} 1 / 4 \mathrm{SRD}$ (21), 3/4 Bo X $1 / 4 \mathrm{SRD}$ (22) e SRD (21), este último como grupo controle, e abatidos com três diferentes pesos de abate: 20,25 e $30 \mathrm{~kg}$ de peso vivo. O trabalho foi conduzido na Fazenda Experimental Vale do Curu, pertencente à Universidade Federal do Ceará-UFC. Os animais experimentais foram mantidos pós-desmame em pastagem nativa raleada e, no final da tarde, recebiam uma suplementação alimentar à base de farelo de milho e soja com aproximadamente $16 \%$ de proteína bruta, na quantidade de $300 \mathrm{~g} \mathrm{cab}^{-1} \mathrm{dia}^{-1}$. No final do período préabate, os animais receberam uma alimentação de terminação constituída de concentrado comercial (50\%) na quantidade de $500 \mathrm{~g} \mathrm{cab}^{-1} \mathrm{dia}^{-1}$, além de feno de leucena moído (25\%) e feno de capim-elefante moído (25\%). Os animais foram abatidos à medida que atingiam os pesos corporais pré-determinados: 20, 25 e 30kg. A idade média de abate dos caprinos foi de 350 dias, com valores variados entre os grupos genéticos (GG) e os pesos de abate (PA).

Os animais foram submetidos a jejum e dieta hídrica 18 horas antes do abate e, após o abate, procedeu-se à esfola e à evisceração. A carcaça foi obtida após a retirada das vísceras, patas, cabeça e pele, sendo imediatamente avaliada a conformação (C) e obtido o peso da carcaça quente (PCQ). Após obtenção do PCQ, as carcaças foram envolvidas em sacos de polietileno e mantidas em câmara fria por 24 horas, à temperatura de $2 \mathrm{a} 4^{\circ} \mathrm{C}$, para a determinação do peso da carcaça fria (PCF). Pela diferença entre PCQ e PCF, foram obtidos as perdas por resfriamento (PR), expressas em percentagem.

Os dados de PA, PCQ, Rendimento quente e frio, PCF, PR e C foram analisados através do método de quadrados mínimos pelo procedimento GLM do pacote estatístico SAS (1999) e as comparações de médias feitas pelo teste " $t$ " de Student, considerandose os efeitos contidos no modelo utilizado. A conformação das carcaças foi avaliada visualmente conforme a metodologia descrita por OSÓRIO et al. (1998) e foram realizadas por dois técnicos com ampla experiência.

Ciência Rural, v.38, n.4, jul, 2008. 


\section{RESULTADOS E DISCUSSÃO}

Não houve interação significativa entre grupo genético e peso de abate em todas as variáveis estudadas. Portanto, as variáveis são apresentadas e discutidas separadamente em função do grupo genético e do peso de abate. A tabela 1 mostra os valores de diferentes características de carcaça, segundo o grupo genético dos animais.

O rendimento da carcaça pode ser influenciado pelo genótipo do animal, conforme reportaram DHANDA et al. (2003). Neste trabalho, cabritos mestiços 3/4 Boer e 3/4 AN apresentaram rendimentos de carcaça quente $\mathrm{e}$ fria superiores $(\mathrm{P}<0,05)$ aos do grupo SRD, porém não se observaram diferenças significativas $(\mathrm{P}>0,05)$ entre os grupos mestiços.

Os maiores valores de características de carcaça encontrados nos cabritos mestiços podem ser explicados pelo fato de as raças paternas serem mais precoces e apresentarem maior desenvolvimento muscular que os SRD. Neste trabalho, os cabritos mestiços $3 / 4$ Anglo-Nubiana e 3/4 Boer mostraram-se mais precoces, com médias de idade ao abate inferiores ( \pm 107 dias) às do grupo SRD. Os resultados mostram claramente que os caprinos SRD apresentam como característica fisiológica um desenvolvimento corporal tardio.

Todavia, mesmo tendo valores inferiores, o rendimento de carcaça quente dos cabritos SRD é superior aos relatados para caprinos da mesma categoria e faixa de peso, no Estado do Ceará, mantidos em condições extensivas de criação (SANTOS FILHO et al., 1999). Diferenças de rendimentos de carcaças entre animais da mesma raça e idade deve serem esperadas nos trabalhos de pesquisa pelas diferenças naturais de ambiente, manejo e maturidade fisiológica dos animais (LEME et al., 2000).
Não houve diferenças $(\mathrm{P}>0,05)$ entre os cabritos mestiços Boer e Anglo-Nubiano em nenhuma das características de carcaça estudadas. O maior rendimento de carcaça esperado nos cabritos mestiços Boer sobre os Anglo-Nubianos, pelo fato de ser uma raça mais especializada para carne, não foi observado. Isso provavelmente deve-se ao baixo vigor híbrido que possui esta característica (ANOUS \& MOURAD, 1993) ou à alimentação não ter sido suficiente para atender as maiores exigências nutricionais da raça Boer. Inexistência de diferenças significativas entre grupos mestiços foi observada também em ovinos (SIQUEIRA et al., 2001) e bovinos (LUCHIARI FILHO et al., 1985).

As perdas de peso por resfriamento das carcaças dos caprinos $(\mathrm{P}>0,05)$ foram similares entre os grupos genéticos, com valor médio de 2,01\%, resultado semelhante aos relatados por FERNANDES et al. (2005) em cabritos mestiços Boer x Saanen, porém inferiores aos 3,1\% obtidos por GRANDE et al. (2003) em cabritos Saanen e por DHANDA et al. (2003) em mestiços Boer (2,6 a 3,7\%). Os valores de perda por resfriamento, que afeta o rendimento comercial da carcaça, podem ser considerados bons para caprinos, tendo-se em vista que, em ovinos de raças de corte, os valores considerados como perdas aceitáveis são de 3 a 4\%, de acordo com SAÑUDO et al. (1981). Além disso, os resultados mostram que, apesar da reduzida quantidade de gordura subcutânea observada nas carcaças dos caprinos, as perdas por resfriamento não foram afetadas ( $\mathrm{P}>0,05)$ em todos os grupos estudados.

Da mesma forma que o rendimento, a conformação da carcaça foi superior $(\mathrm{P}<0,05)$ nos cabritos mestiços Anglo-Nubiano e Boer sobre os SRD, fato observado pela maior estrutura para carne das raças especializadas para corte. Verificou-se que as carcaças do grupo mestiço Boer eram mais compactas que as do

Tabela 1 - Média e coeficiente de variação de peso e rendimento de carcaça de caprinos de diferentes grupos genéticos.

\begin{tabular}{|c|c|c|c|c|}
\hline \multirow{2}{*}{ Características } & \multicolumn{3}{|c|}{------------------------------'Grupo genético----------------------------' } & \multirow{2}{*}{ CV (\%) } \\
\hline & 3/4 A-Nubiana & $3 / 4$ Boer & SRD & \\
\hline Peso Carcaça Quente (kg) & $11,51 \mathrm{a}$ & $11,53 \mathrm{a}$ & $10,74 \mathrm{a}$ & 7,42 \\
\hline Rendimento Carcaça Quente(\%) & $45,60 \mathrm{a}$ & 45,86 a & $43,34 \mathrm{~b}$ & 3,81 \\
\hline Peso Carcaça Fria (kg) & 11,29 a & 11,31a & $10,50 \mathrm{a}$ & 7,54 \\
\hline Rendimento Carcaça Fria (\%) & 44,73 a & 44,96 a & $42,34 \mathrm{~b}$ & 3,81 \\
\hline Perdas por resfriamento (\%) & $1,90 \mathrm{a}$ & 1,97 a & 2,17 a & 24,36 \\
\hline Conformação & $3,51 \mathrm{a}$ & $3,72 \mathrm{a}$ & $3,05 \mathrm{~b}$ & 11,85 \\
\hline
\end{tabular}

* Letras iguais na mesma linha não diferem estatisticamente entre os grupos pelo teste “t” ( $\mathrm{P}<0,05)$. 
Anglo-Nubiano, fato demonstrado pelo seu menor comprimento e pela maior compacidade aparente, características consideradas importantes nas raças especializadas para carne.

O efeito do peso de abate nas diferentes características de carcaça de caprinos é mostrado na tabela 2. Caprinos abatidos nas faixas de peso de $25 \mathrm{e}$ de $30 \mathrm{~kg}$ de peso vivo apresentaram rendimento e conformação de carcaça quente e fria superiores $(\mathrm{P}<0,05)$ aos abatidos com $20 \mathrm{~kg}$.

O aumento do peso corporal melhora o rendimento e a conformação da carcaça, conforme estudos com diversas espécies de animais (BUENO et al., 1997 e DHANDA et al., 2003, em caprinos; OLIVEIRA et al.,1998 e LLOYD et al., 1980, com ovinos). Os resultados obtidos neste trabalho mostraram que o rendimento da carcaça aumentou até o peso de $25 \mathrm{~kg}$, faixa de peso provável em que o tecido muscular tenha atingido o seu desenvolvimento máximo.

O rendimento de carcaça fria manteve-se, na mesma proporcionalidade, inferior ao rendimento quente, sendo menor nos animais abatidos com $20 \mathrm{~kg}$ e similares entre os pesos de 25 e $30 \mathrm{~kg}$ (Tabela 2). As perdas por resfriamento foram similares entre as carcaças de caprinos abatidos nos diferentes pesos ao abate. Isso pode ter ocorrido em virtude da reduzida gordura de cobertura nas carcaças. Em animais mais jovens, a perda pelo resfriamento tende a ser maior (GRANDE et al., 2003).

Na avaliação da conformação da carcaça, aspecto importante de qualidade, foi observada maior quantidade de carcaças superiores nos caprinos abatidos com 25 e 30kg de peso, que apresentaram uma melhor conformação, provavelmente, pelo maior volume de tecido muscular. No grupo de $20 \mathrm{~kg}$ de peso vivo, que corresponde a animais mais jovens, a conformação inferior deve-se possivelmente ao processo de formação do tecido muscular ainda não ter sido completado na sua magnitude. À semelhança do rendimento, os resultados mostraram que o aumento de peso de abate dos animais afetou a conformação somente até determinada idade.

Aspectos relacionados à idade de abate foram observados quando o grupo SRD apresentou idade mais elevada em todas as faixas de peso estudadas (422 dias), com pouca diferença entre os grupos $3 / 4$ Anglo-Nubiana e 3/4 Boer (321 e 310 dias, respectivamente). Este resultado pode ser justificado devido aos caprinos SRD, por serem animais menos especializados para produção de carne, apresentarem um desenvolvimento corporal mais tardio, implicando uma maior idade para atingir o peso de abate aceito pelo mercado consumidor.

O peso de abate dos animais foi atingido a uma idade muito avançada em relação à média de $28 \mathrm{~kg}$ com 180 dias, considerados como peso e idade economicamente mais eficientes para o abate de ovinos (SIQUEIRA et al., 2001). No entanto, o sistema de criação utilizado neste trabalho pode ter contribuído para o retardamento da idade de abate nos pesos prédeterminados dos animais.

\section{CONCLUSÃO}

Cabritos mestiços oriundos do cruzamento de reprodutores das raças Anglo Nubiana e Boer com cabras Sem Padrão Racial Definido apresentam carcaças de melhor rendimento e conformação, além de maior precocidade, que os cabritos SRD, mostrando ser o cruzamento uma ferramenta eficiente para melhorar a produção de carne desses animais.

O rendimento e a conformação da carcaça de caprinos aumentam à medida que aumenta o peso de abate dos animais até os $25 \mathrm{~kg}$ de peso vivo.

Tabela 2 - Média e coeficiente de variação de peso e rendimento de carcaça de caprinos abatidos com diferentes pesos.

\begin{tabular}{|c|c|c|c|c|}
\hline Variáves & $20 \mathrm{~kg}$ & $25 \mathrm{~kg}$ & $30 \mathrm{~kg}$ & $\mathrm{CV}(\%)$ \\
\hline Peso carcaça quente (kg) & $8,91 \mathrm{c}$ & $10,97 \mathrm{~b}$ & $13,90 \mathrm{a}$ & 7,42 \\
\hline Rendimento carcaça quente (\%) & $43,82 \mathrm{~b}$ & 45,15 a & 45,82 a & 3,81 \\
\hline Peso carcaça fria (kg) & $8,72 \mathrm{c}$ & $10,75 \mathrm{~b}$ & 13,63 a & 7,54 \\
\hline Rendimento carcaça fria (\%) & $42,90 \mathrm{~b}$ & $44,21 \mathrm{a}$ & $44,91 \mathrm{a}$ & 3,81 \\
\hline Perdas por resfriamento (\%) & $2,06 \mathrm{a}$ & $2,08 \mathrm{a}$ & $1,92 \mathrm{a}$ & 24,36 \\
\hline Conformação & $2,95 \mathrm{~b}$ & 3,53 a & 3,79 a & 11,85 \\
\hline
\end{tabular}

*Letras iguais na mesma linha não diferem estatisticamente entre os grupos pelo teste “t” $(\mathrm{P}<0,05)$.

Ciência Rural, v.38, n.4, jul, 2008. 


\section{REFERÊNCIAS}

ANOUS, M.R.; MOURAD, M.M. Crossbreeding effects on reprodutive traits of does and growth and carcass traits of kids. Small Ruminant Research, v.12. p.141-149, 1993.

ARAÚJO FILHO, J.A. et al. Pastoreio misto em caatinga manipulada no sertão cearense. Revista Científica de Produção Animal, 4, n.01-02, p.9-21, 2002.

BUENO, M.S. et al. Avaliação da carcaça de cabritos abatidos com diferentes pesos vivos. Boletim da Indústria Animal, v.54. n.2, p.61-67, 1997.

CARDELLINO, R.A. Produccion de carne ovina basada en cruzamientos. In: JORNADAS CIENTÍfICAS DE LA SOCIEDAD ESPAÑOLA DE OVINOTECNIA. Selección de Temas Agropecuários. Montevideo: Hemisferio Sur, 1989. 520p.

DHANDA, J.S. et al. Part 1. Growth, carcass and meat quality parameters of male goats: effects of genotype and liveweight at slaughter. Small Ruminant Research, v.50, p.57-66, 2003.

FERNANDES, M.H.M.R. et al. Desempenho e rendimento de carcaça de cabritos $3 / 4$ Boer $1 / 4$ Saanen abatidos com diferentes pesos. In. REUNIÃO DA SOCIEDADE BRASILEIRA DE ZOOTECNIA, 2005, Goiânia. Anais... Goiânia: SBZ, 2005. (CD ROOM).

GRANDE, A.P. et al. Desempenho e características de carcaças de cabritos saanen recebendo rações com farelo de glúten de milho e/ou farelo de soja. Acta Scientiarum. Animal Sciences, Maringá, v.25, n.2, p.315-321, 2003.

LEME, P.R. et al. Desempenho em confinamento e características de carcaça de bovinos machos de diferentes cruzamentos abatidos em três faixas de peso. Revista Brasileira de Zootecnia, v.29. n.6, (suplemento 2), p.23472353, 2000

LLOYD, W.R. et al. Effect of breed, sex and final weight on feedlot performance, carcass characteristic and meat palatability of lambs. Journal of Animal Science, v.51, n.2, p.316-320, 1980 .
LUCHIARI FILHO, A. et al. Efeito do tipo de animal no rendimento da porção comestível da carcaça. 1.Machos da raça Nelore vs mestiços zebu x europeu terminados a pasto. Boletim da Indústria Animal, v.42. n.2, p.143-148, 1985.

OLIVEIRA, N.M. et al. Produção de carne em ovinos de cinco genótipos. 5. Estimativas de qualidade e peso de carcaça através do peso vivo. Ciência Rural, v.28, n.4, p.665-669, 1998.

OSÓRIO, J.C.S. et al. Métodos para avaliação da produção da carne ovina: in vivo, na carcaça e na carne. Pelotas: UFPEL, 1998. 99p.

SAINZ, R.D. Qualidade das carcaças e da carne caprina e ovina. In: REUNIÃO ANUAL DA SBZ; SIMPÓSIO INTERNACIONAL SOBRE TÓPICOS ESPECIAIS EM ZOOTECNIA, 1996, Fortaleza. Anais... Fortaleza: SBZ, 1996. p.3-14

SANTOS FILHO, J.M. et al. Efeito do peso vivo ao abate sobre as características quantitativas da carcaça em caprinos Sem Raça Definida no Estado do Ceará. Revista Científica de Produção Animal, v.1, n.2, p.147-153, 1999.

SAÑUDO, C. et al. Estudio de la calidad de la canal y de la carne en animales cruzados Romanov por Rasa Aragonesa. 2. Comparación en el tipo comercial ternasco com Rasa en pureza. In: JORNADAS CIENTÍFICAS DE LA SOCIEDAD ESPAÑOLA DE OVINOTECNIA, 7., 1981, Talavera de la Reina. Espanha. Actas... Talavera de la Reina: Facultad de veterinaria, 1981. p.483-489.

SAÑUDO, C.; SIERRA, I. Calidad de la canal en la especie ovina. Ovino, v.1, p.127-153, 1986.

SILVA SOBRINHO, A.G. Aspectos quantitativos e qualitativos da produção de carne ovina. 2001. In: A PRODUÇÃO ANIMAL NA VISÃO DOS BRASILEIROS, 2001, Piracicaba. Anais... Piracicaba: FEALQ, 2001. p.425-446.

SIQUEIRA, E.R. et al. Efeito do sexo e do peso ao abate sobre a produção de carne de cordeiro.I. Velocidade de crescimento, caracteres quantitativos da carcaça, $\mathrm{pH}$ da carne e resultado econômico. Revista Brasileira de Zootecnia, v.30, n.3, p.844-848, 2001.

SAS. Institute Inc. Introductory Guide for Personal Computers. Version 8.ed. Cary, NC, 1999. 1167p. 